\title{
Causes of Neonatal Deaths in a Rural Subdistrict of Bangladesh: Implications for Intervention
}

\author{
Hafizur Rahman Chowdhury',2, Sandra Thompson', Mohammed Ali', \\ Nurul Alam², Md.Yunus², and Peter Kim Streatfield ${ }^{2}$ \\ 'Centre for International Health, Curtin University of Technology, GPO Box UI 987, Perth, Australia and \\ ${ }^{2}$ ICDDR,B, GPO Box I28, Dhaka I000, Bangladesh
}

\begin{abstract}
The study assessed the timing and causes of neonatal deaths in a rural area of Bangladesh. A populationbased demographic surveillance system, run by the International Centre for Diarrhoeal Disease Research, Bangladesh, recorded livebirths and neonatal deaths during 2003-2004 among a population of 224,000 living in Matlab, a rural subdistrict of eastern Bangladesh. Deaths were investigated using the INDEPTH/ World Health Organization verbal autopsy. Three physicians independently reviewed data from verbal autopsy interview to assign the cause of death. There were 11,291 livebirths and 365 neonatal deaths during the two-year period. The neonatal mortality rate was 32.3 per 1,000 livebirths. Thirty-seven percent of the neonatal deaths occurred within 24 hours, $76 \%$ within $0-3$ days, $84 \%$ within $0-7$ days, and the remaining $16 \%$ within 8-28 days. Birth asphyxia (45\%), prematurity/low birthweight (15\%), sepsis/meningitis (12\%), respiratory distress syndrome (7\%), and pneumonia (6\%) were the major direct causes of death. Birth asphyxia (52.8\%) was the single largest category of cause of death in the early neonatal period while meningitis/sepsis (48.3\%) was the single largest category in the late neonatal period. The high proportion of deaths during the early neonatal period and the far-higher proportion of neonatal deaths caused by birth asphyxia compared to the global average (45\% vs $23-29 \%$ ) indicate the lack of skilled birth attendance and newborn care for the large majority of births that occur in the home in rural Bangladesh. Resuscitation of newborns and management of low-birthweight/premature babies need to be at the core of neonatal interventional packages in rural Bangladesh.
\end{abstract}

Key words: Causes of death; Interventions; Neonatal mortality; Verbal autopsy; Bangladesh

\section{INTRODUCTION}

Deaths of newborns within 28 days of birth are a major barrier to improving the survival of children aged less than five years (under-five children) in developing countries. Neonatal deaths now account for more than two-thirds of all deaths in the first year of life and for about half of all deaths in underfive children $(1,2)$. Bangladesh has a neonatal mortality rate of 41 per 1,000 livebirths, and neonatal deaths account for about half of deaths of underfive children (3). Therefore, appropriate interventions are crucial for improving the health of underfive children in Bangladesh and to help achieve the

Correspondence and reprint requests should be addressed to:

Dr. Hafizur Rahman Chowdhury

Doctoral Research Fellow

Centre for International Health,

Curtin University of Technology

GPO Box U1987, Perth 6845

Western Australia

Email: hafiz@icddrb.org global target of reducing under-five mortality by two-thirds. Information on the timing and causes of neonatal deaths can help direct appropriate interventions.

According to the World Health Organization (WHO), preterm birth accounts for 30\% of global neonatal deaths, sepsis or pneumonia for $27 \%$, birth asphyxia for $23 \%$, congenital abnormality for $6 \%$, neonatal tetanus for $4 \%$, diarrhoea for $3 \%$, and other causes for $7 \%$ of all neonatal deaths $(2,4,5)$. However, these estimates are based on limited datasets as most births and neonatal deaths occur in the home or outside formal health settings in developing countries $(4,5)$. In this regard, verbal autopsy (VA) can be an appropriate and cost-effective tool as it uses a retrospective interview of family members about the circumstances of a death to ascertain the cause of death. The tool has been used successfully in many developing countries for generating reliable epidemiological data on mortality $(6,7)$.

This paper describes the results of a VA study, particularly the direct cause of death and its timing, 
carried out on all neonatal deaths during 20032004 in a rural subdistrict of Bangladesh.

\section{MATERIALS AND METHODS}

\section{Study design and population}

The study was carried out in Matlab, a rural subdistrict in eastern Bangladesh, where the International Centre for Diarrhoeal Disease Research, Bangladesh (ICDDR,B) has been maintaining a longitudinal health and demographic surveillance system (HDSS) on 224,000 people living in the area (8). Approximately half of the surveillance population $(n=112,000)$ receives a range of maternal and child-health and family-planning intervention services from ICDDR,B, and the remaining half receives standard government services (8). The demographic surveillance system is maintained at the peripheral level by the Community Health Research Workers (CHRWs) who make monthly visits to households to collect information on demographic events, such as birth, death, migration, abortion, marriage, divorce, etc., using pre-coded coloured forms to record the events. Living in the village and having a limited population to survey, these CHRWs are very unlikely to miss any vital events. These data are collated and maintained in the HDSS databases (8). The CHRWs collect data from both ICDDR,B and government service areas. This study investigated and analyzed all neonatal deaths in 2003 and 2004 in both intervention and comparison areas of the HDSS. The total number of neonatal deaths was 365 .

\section{Verbal autopsy}

The questionnaire was developed by a VA working group of the International Network of Field Sites with Continuous Demographic Evaluation of Populations and their Health in developing countries INDEPTH (http://www.indepth-network.org) and is closely based on the WHO VA questionnaire. For use in the Matlab HDSS, the questionnaire was adapted to local customs and culture and was translated into Bangla by a VA team at the Matlab HDSS before its piloting and implementation in the HDSS. The questionnaire included space for an open-ended description of deaths and a closedended component on pregnancy, child birth, and common illnesses of neonatal deaths. A structured one-page questionnaire was also included for collecting information on healthcare-seeking during the fatal illness episode.

\section{Collection of data}

The CHRWs recorded any deaths in their assigned territory of households on a registration slip (date of death, identification number, etc.) during their monthly house-to-house visits, which was then sent to the block supervisor. These were then uploaded on the HDSS records. An interviewer trained in VA and with at least 10 years of schooling made a field-visit 2-6 weeks after the date of death to conduct the VA interview. After obtaining informed verbal consent, the interviewer conducted the interview in Bangla, the local language. Generally, the mother was the primary respondent but sometimes other family members were allowed to supplement the interview. Descriptive statements were recorded in the open part of the questionnaire in Bangla, preserving local idioms and refraining from any alteration or translation. Interviews generally lasted for 40-60 minutes depending on the history of illness and the emotional state of the caretakers.

\section{Assignment of cause of death}

Three physicians independently reviewed all records of deaths to assign a direct cause of death and an originating/underlying cause of death when possible. The physicians worked at the ICDDR,B hospital in Matlab and were aware of the local disease profile of the population. They were also knowledgeable about the integrated management of childhood illness (IMCI) guidelines of the WHO (9). All physicians were given a brief orientation about the VA questionnaire and their responsibilities to allocate a cause of death. Their role was to review the completed VA questionnaire to assign a direct cause of death and an originating cause of death. They used a three-digit code for each cause of death from the list of codes of the tenth revision of International Statistical Classification of Disease, Injuries and Causes of Death (ICD-10) (10). An agreement of at least two physicians on a direct cause of death was required to assign a cause of death.

\section{Analysis of data}

All data were entered via a Visual FoxPro dataentry screen into the Oracle database. For reporting purposes, prematurity and low birthweight were combined into one category, sepsis and meningitis into another category, and all congenital anomalies as one category. Deaths and causes of death were compared by sex of newborn, and the time period of death using $\chi^{2}$ test or Fisher's Exact test when appropriate. Data were analyzed using the Stata software (version 9) (11).

\section{Ethical approval}

The Human Research Ethics Committee of the Curtin University of Technology and the Ethical Review Committee of the ICDDR,B approved the study. Informed verbal consent, confidentiality, and anonymity were ensured for all interviewees. 


\section{RESULTS}

\section{Early and late neonatal mortality rates by} service area

The overall rate of neonatal morality in Matlab was 32.3 per 1,000 livebirths, with 30.6 in the ICDDR,B service area and 34.1 in the government service area. Table 1 shows that the rate of early (0-7 days) neonatal morality was 28.6 per 1,000 livebirths in the government service area, which was $11 \%$ higher than that in the ICDDR,B service area (25.8 per 1,000 during the second week, and the remaining 32 $(8.8 \%)$ occurred in the third and the fourth week of life. Thus, more than four-fifths of the neonatal deaths occurred in the first week, with a large proportion on the day of birth.

\section{Cause of death}

Birth asphyxia (44.9\%), prematurity/low birthweight (15.1\%), sepsis/meningitis (12.3\%), respiratory distress syndrome (RDS) (6.9\%), and pneumonia (5.5\%) were the top five causes of death

\begin{tabular}{|lccc|}
\hline \multicolumn{4}{|c|}{ Table 1. Neonatal mortality rate according to timing of death and service areas } \\
\hline Timing of death & $\begin{array}{c}\text { ICDDR,B area } \\
\text { (livebirth=5,659) }\end{array}$ & $\begin{array}{c}\text { Government area } \\
\text { (livebirth=5,632) }\end{array}$ & $\begin{array}{c}\text { Both areas } \\
\text { (livebirth=11,291) }\end{array}$ \\
\hline $\begin{array}{l}\text { Early (0-7 days) } \\
\text { neonatal mortality rate* }\end{array}$ & 25.8 & 28.6 & 27.2 \\
$\begin{array}{l}\text { Late (8-28 days) } \\
\text { neonatal mortality rate }\end{array}$ & 4.8 & 5.5 & 5.1 \\
Total & 30.6 & 34.1 & 32.3 \\
\hline $\begin{array}{l}\text { The overall difference between areas is insignificant; } \chi^{2}(1)=1.12 ; \mathrm{p}=0.29 ; \\
\text { rate expressed per 1,000 livebirths }\end{array}$
\end{tabular}

livebirths).The rateoflate(8-28days)neonatalmortali ty was 5.5 per 1,000 livebirths in the government area, about $15 \%$ higher than that in the ICDDR,B area (4.8 per 1,000 livebirths). Overall, early neonatal deaths (first seven days of life) comprised $84 \%$ of all neonatal deaths.

\section{Plurality of births}

Most (82\%) deceased neonates were singleton births while twins comprised $16 \%$ of the deaths, and one set of triplets accounted for $2 \%$. Normally, about $1 \%$ of pregnancies result in a multiple birth. Plurality of birth was not significantly different between the ICDDR,B and the government service area.

\section{Age at neonatal death}

Of the 365 neonatal deaths, 136 (37.3\%) occurred on the day of birth, 279 (76.4\%) within the first three days, and 307 (84.1\%) within the first week of life (Fig.). Twenty-six (7.1\%) of the deaths occurred

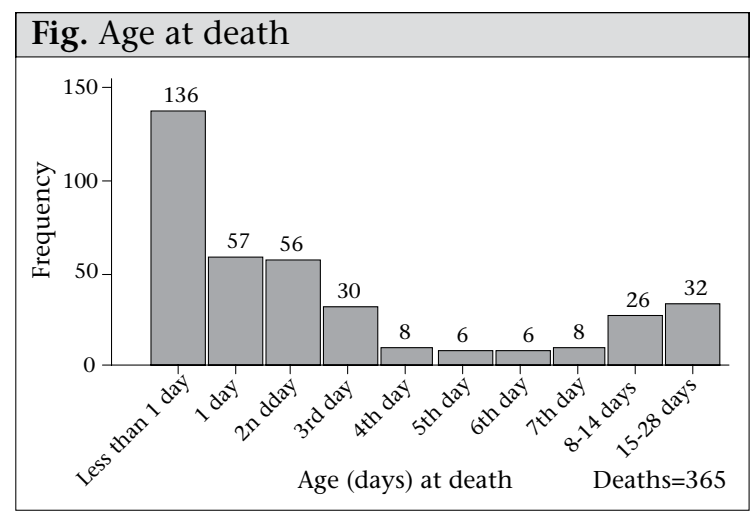

(Table 2). These five causes accounted for $85 \%$ of the cases. The other causes included hypothermia, birth injury, sudden infant death, and congenital anomalies. Around $7 \%$ of the cases were classified

\begin{tabular}{|c|c|c|c|}
\hline Cause of death & No. & $\%$ & 95\% CI \\
\hline Birth asphyxia & 164 & 44.9 & $39.8-50.2$ \\
\hline $\begin{array}{l}\text { Low birthweight/ } \\
\text { prematurity }\end{array}$ & 55 & 15.1 & $11.6-19.2$ \\
\hline Meningitis/sepsis & 45 & 12.3 & $9.1-16.1$ \\
\hline $\begin{array}{l}\text { Respiratory distress } \\
\text { syndrome }\end{array}$ & 25 & 6.9 & $4.5-9.9$ \\
\hline Pneumonia & 20 & 5.5 & $3.4-8.3$ \\
\hline \multicolumn{4}{|l|}{ Others } \\
\hline Hypothermia & 6 & 1.6 & $0.6-3.5$ \\
\hline Birth injury & 4 & 1.1 & $0.3-2.8$ \\
\hline $\begin{array}{l}\text { Sudden infant } \\
\text { death }\end{array}$ & 4 & 1.1 & $0.3-2.8$ \\
\hline $\begin{array}{l}\text { Congenital } \\
\text { abnormality }\end{array}$ & 3 & 0.8 & $0.2-2.4$ \\
\hline Other specified ${ }^{*}$ & 6 & 1.6 & $1.0-4.3$ \\
\hline Undetermined $\dagger^{\dagger}$ & 26 & 7.1 & $4.7-10.3$ \\
\hline $\begin{array}{l}\text { No cause } \\
\text { (unspecified) }\end{array}$ & 7 & 1.9 & $0.4-3.2$ \\
\hline Total & 365 & 100 & \\
\hline \multicolumn{4}{|c|}{$\begin{array}{l}\text { *Neonatal aspiration syndrome }(\mathrm{n}=4) \text {, neonatal } \\
\text { jaundice }(\mathrm{n}=1) \text {, and neonatal hypoglycaemia } \\
(\mathrm{n}=1) ; \text { † No agreement between physicians; } \mathrm{CI}= \\
\text { Confidence interval }\end{array}$} \\
\hline
\end{tabular}


as undetermined as there was no agreement between any of the physicians on the cause assigned. In $1.9 \%$ of the cases, the physicians were unable to assign any cause.

\section{Cause of death by sex of newborn}

There were substantial differences in cause of death when gender was considered (Table 3). Overall, the of causes of death (Table 4) by early and late neonatal periods and across categories of cause of death. These differences were significant [ (Pearson $\chi^{2}(5)=130.95 ; p<0.01$; Fisher's Exact $\left.\left.\mathrm{p}=0.001\right)\right]$. Birth asphyxia (52.8\%) was the single largest category of cause of death in the early neonatal period while sepsis/meningitis (48.3\%) was the single largest category in the late neonatal period.

\begin{tabular}{|c|c|c|c|c|c|c|}
\hline \multirow{2}{*}{ Cause of death } & \multicolumn{2}{|c|}{ Male $(n=200)$} & \multicolumn{2}{|c|}{ Female $(n=100)$} & \multicolumn{2}{|c|}{ Both $(n=365)$} \\
\hline & No. & $\%$ & No. & $\%$ & No. & $\%$ \\
\hline Birth asphyxia & 102 & 51.0 & 62 & 37.6 & 164 & 44.9 \\
\hline Prematurity/low birthweight & 31 & 15.5 & 24 & 14.5 & 55 & 15.1 \\
\hline Meningitis/sepsis & 20 & 10.0 & 25 & 15.2 & 45 & 12.3 \\
\hline Pneumonia & 14 & 7.0 & 6 & 3.6 & 20 & 5.5 \\
\hline Respiratory distress syndrome & 13 & 6.5 & 12 & 7.3 & 25 & 6.8 \\
\hline Others & 20 & 10.0 & 36 & 21.8 & 56 & 15.3 \\
\hline
\end{tabular}

number of male deaths was 200 compared to 165 female deaths; the males accounted for a larger proportion (54.8\%) of all deaths. The following causes of death were proportionately less among females than among males: birth asphyxia (37.6\% vs $51 \%)$, low birthweight/prematurity (14.5\% vs $15.5 \%)$, and pneumonia (3.6\% vs $7.0 \%$ ) while the following causes were proportionately greater among females: sepsis/meningitis (15.2\% vs $10 \%)$, respiratory distress syndrome $(7.3 \%$ vs $6.5 \%)$, and other causes $(21.8 \%$ vs $10 \%)$. Overall, the difference in the proportions of death across cause of death by gender was significant $\left(\right.$ Pearson $\left.\chi^{2}(5)=15.80 ; \mathrm{p}<0.01\right)$.

Cause of death by early and late neonatal periods

There were major differences in the distribution

\section{DISCUSSION}

\section{Neonatal mortality rate}

The neonatal mortality rate of 32.3 per 1,000 livebirths during 2003-2004 in Matlab was lower than the national neonatal mortality rate of 41 per 1,000 livebirths and approximated the global average of $33(2,3)$. What was particularly encouraging was that this figure represented a $21 \%$ reduction in the neonatal mortality rate between 1996 and 2004 in the same area (12), largely as a result of the high coverage of maternal and child-health $(\mathrm{MCH})$ outreach services, albeit with a relatively low rate of skilled/instrumental delivery. The low neonatal mortality rate in the $\mathrm{MCH}-\mathrm{FP}$ project area in our study compared to the government area may also

\begin{tabular}{|c|c|c|c|c|c|c|}
\hline \multirow[t]{2}{*}{ Cause of death } & \multicolumn{2}{|c|}{$\begin{array}{c}\text { Early (0-7 days) } \\
(\mathrm{n}=307)\end{array}$} & \multicolumn{2}{|c|}{$\begin{array}{c}\text { Late (8-28 days) } \\
(\mathrm{n}=58)\end{array}$} & \multicolumn{2}{|c|}{$\begin{array}{l}\text { Both periods } \\
(\mathrm{n}=365)\end{array}$} \\
\hline & No. & $\%$ & No. & $\%$ & No. & $\%$ \\
\hline Birth asphyxia & 162 & 52.8 & 2 & 3.4 & 164 & 44.9 \\
\hline $\begin{array}{l}\text { Prematurity/low } \\
\text { birthweight }\end{array}$ & 52 & 16.9 & 3 & 5.2 & 55 & 15.1 \\
\hline $\begin{array}{l}\text { Respiratory distress } \\
\text { syndrome }\end{array}$ & 24 & 7.8 & 1 & 1.7 & 25 & 6.8 \\
\hline Meningitis/sepsis & 17 & 5.5 & 28 & 48.3 & 45 & 12.3 \\
\hline Pneumonia & 9 & 2.9 & 11 & 19.0 & 20 & 5.5 \\
\hline Others & 43 & 14.0 & 13 & 22.4 & 56 & 15.3 \\
\hline Specified (rare) & 17 & 5.5 & 6 & 10.3 & 23 & 6.3 \\
\hline Undetermined & 20 & 6.5 & 6 & 10.3 & 26 & 7.1 \\
\hline No cause & 6 & 1.9 & 1 & 1.7 & 7 & 1.9 \\
\hline
\end{tabular}


have been due to the relatively higher use of $\mathrm{MCH}$ outreach services and primary-care facilities, including basic obstetric care facilities in the former (13).

\section{Causes of neonatal death}

The proportional distribution of the major causes of neonatal deaths in our study differed somewhat from the WHO-derived global estimates, with important public-health implications. Birth asphyxia accounted for a far larger proportion (45\%) of neonatal deaths in Matlab compared to the global average of $23-29 \%(2,5)$. The recent survey in Bangladesh referred earlier also showed a higher proportion (39\%) of deaths due to this cause (14). Another nationwide perinatal survey in South Africa, conducted during 1999-2003, also reported that asphyxia-hypoxia was responsible for about onethird of neonatal deaths (15). This higher rate of deaths due to birth asphyxia in our study in Bangladesh and in similar developing countries reflects the lack of appropriate resuscitation care for newborns at birth where the great majority of deliveries are conducted in the home with no skilled birth attendance. Also, the high proportion of births that are low weight/premature in Matlab would have contributed to a higher incidence of birth asphyxia as shown in an earlier study in the country (16).

Yet another factor in the case of neonatal fatalities occurring at health facilities is in relation to the inappropriate use of intravenous medications for augmenting the progress of labour. A recent study in India found that unnecessary administration of oxytocics to augment labour was associated with a three-fold increase [odds ratio $(O R)=2.6$; 95\% confidence interval (CI) 1.9-3.6] in birth asphyxiarelated deaths (17). An earlier study in Bangladesh also indicated that the trial of labour was associated with an increased risk of neonatal death in health facilities in a rural subdistrict of Bangladesh (18). Results of a recent study in South Africa indicate that inadequate foetal monitoring by health workers is an important avoidable factor associated with birth asphyxia-related deaths (15).

\section{Premature birth/low birthweight}

Prematurity/low birthweight was a cause of death in $15 \%$ of the neonatal deaths in our study, which is much lower than the global average of around $27 \%$ of neonatal deaths $(2,5)$. It is also lower than those obtained from recent studies in India (19) and Bangladesh (14) where $27 \%$ of neonatal deaths were attributed to low birthweight/prematurity. This could have been due to the use of a separate category of respiratory distress syndrome as a cause of death that is usually also associated with prematurity, and this would have left a fewer cases to be assigned to low birthweight/prematurity. Also, it cannot be ruled out that the physicians may have exercised a higher subjective threshold for picking up low-birthweight and premature babies as a cause of death

\section{Infections}

Nearly one-fifth (20.5\%) of the deaths in our study were due to infectious diseases, such as sepsis, meningitis, and pneumonia, which underscores the general decline in deaths due to infectious diseases in the country, from a high of $48.9 \%$ of all neonatal deaths observed in 1992-1993 in rural Bangladesh (20) and which can be attributed to almost total elimination of tetanus since the introduction of prophylaxis for maternal tetanus. This remains an area for potential intervention to reduce the number of neonatal deaths.

\section{Unspecified cause}

The physicians in our study failed to assign a cause (unspecified) in 1.9\% of the deaths, and for another $7.1 \%$ of the cases, the cause was listed as undetermined, as they differed on a cause of death. The unspecified proportion (1.9\%) is consistent with the latest nationwide neonatal VA survey, which reported $3.4 \%$ of neonatal death as unspecified (3). The nationwide VA survey and this study used a similar modular VA tool in collecting information before neonatal death. The use of the new VA tool with a combination of structured questions and open-ended description of symptoms and events yields greater information, including information on healthcare-seeking which enables physicians to allocate a cause for a higher proportion of neonatal deaths. Also, the option to choose a cause of death from an almost unrestricted pool of codes within the ICD-10 classification may have enabled physicians to specify a cause for a greater proportion of neonatal deaths.

While physician's review was considered to be the reference standard in this study, it should be appreciated that assigning the cause of death by the physicians was a largely subjective process, despite the steps taken by the study to ensure uniformity and standardization of the physician's review process.

\section{Cause of death by sex}

The study found that the female neonates had a lower risk of dying than the male ones. Although the study did not assess the factors responsible for such differences, this difference, which is universally reported, is due to biological advantages enjoyed by female infants and the increased vulnerability of male infants in their early life to environmental 
stresses (21). The explanation of these differentials in cause of death between the sexes observed in this study goes beyond the scope of the study.

\section{Cause of death by early and late neonatal period}

The clustering of deaths found in our study around the early neonatal period mainly due to birth asphyxia and prematurity/low birthweight has been reported from many developing countries (2). This highlights the need for a more focused newborncare strategy where resuscitation care for birth asphyxia and appropriate management of premature and low-birthweight babies can be made universally available at the household level in developing countries, where deliveries in the home tend to be the norm. In this regard, the use of community health workers to provide home-based care for both birth asphyxia and small size at birth is worth considering $(17,22)$.

\section{Targeted interventions}

A significant proportion of neonatal deaths could be avoided by appropriate resuscitation care. Most asphyxiated neonates can be successfully resuscitated by simple cost-effective measures, such as clearing the airways, drying and stimulating baby by rubbing with a towel to make the baby crying, and, in some cases, by positive pressure ventilation either through mouth-to-mouth breathing or through use of bag and mask (23). Studies in Indonesia and India have demonstrated the effectiveness of using teams of village health workers and traditional birth attendants in reducing the number of deaths due to asphyxia at the community level $(17,24)$.

There is a range of evidence-based interventions available that can improve the survival of premature/low-birthweight babies. The promotion of early and exclusive breastfeeding $(25,26)$, prevention and treatment of hypothermia, including kangaroo mother care (26-28), topical skin-cleansing with chlorhexidine (30), and topical emollient (sunflower oil) treatment for hospitalized infants (31) may reduce morbidity and mortality among low-birthweight and premature infants. Result of a recent community-based study in India provides further evidence that home-based management of low-birthweight and preterm neonates with supportive care and treatment of infections is feasible and effective in improving the survival of newborns (22).

Although infectious causes (sepsis/meningitis and pneumonia) were the major contributor to late neonatal deaths in our study, these are also important in early neonatal deaths. Most early infections are usually acquired from the mother, and management of maternal reproductive and urinary tract infections can, thus, be effective in preventing infections in neonates (32). In addition, community-based studies in developing countries have reported that clean delivery practices (hand-washing and cleaning birth-passages with chlorhexidine) and neonatal care practice just after delivery (clean cord-cutting, applying chlorhexidine over the cord, and skincleansing) can also reduce neonatal infections and infection-related mortality $(25,30,31)$. Late neonatal deaths due to neonatal tetanus can be successfully prevented by tetanus toxoid immunization of the pregnant mother and through cleanliness in cord-care $(25,30)$. Although the WHO advocates that very severe neonatal illnesses, including sepsis, be treated in a hospital $(33,34)$, community-based management of sepsis using trained village health workers has been shown to be effective in reducing neonatal mortality $(25,35,36)$.

In summary, for Matlab or similar settings, an integrated package of targeted neonatal interventions for birth asphyxia, prematurity, low birthweight, and infections is key to substantially reducing neonatal mortality. The recommendations for reducing the number of neonatal deaths discussed above require not just health/technical intervention but political commitment to make neonatal and child health a greater priority. Socioeconomic and developmental factors limit the access to and availability of health/technical interventions. Therefore, substantial reduction in neonatal mortality requires health programmes combined with other socioeconomic development activities for the population that facilitate individual and community control over factors determining health.

\section{ACKNOWLEDGEMENTS}

The authors acknowledge the contribution of the study participations. This study was funded by ICDDR,B and its donors which provide unrestricted support to the Centre for its operations and research. Current donors providing unrestricted support include: Australian Agency for International Development (AusAID), Government of the People's Republic of Bangladesh, Canadian International Development Agency (CIDA), Embassy of the Kingdom of the Netherlands (EKN), Swedish International Development Cooperation Agency (Sida), and Department for International Development (DFID), UK. The authors gratefully acknowledge these donors for their support and commitment to the Centre's research efforts. The principal investigator was supported by ICDDR,B and International Postgraduate Research Scholarship (IPRS), Government of Australia. 


\section{REFERENCES}

1. Darmstadt GL, Lawn JE, Costello A. Advancing the state of the world's newborns. Bull World Health Organ 2003;81:224-5.

2. Lawn JE, Cousens S, Zupan J; Lancet Neonatal Survival Steering Team. 4 million neonatal deaths: when? Where? Why? Lancet 2005;365:891-900.

3. National Institute of Population Research and Training. Bangladesh demographic and health survey 2004. Dhaka: National Institute of Population Research and Training, 2005. $342 \mathrm{p}$.

4. World Health Organization. The world health report: 2005: make every mother and child count. Geneva: World Health Organization, 2005. 219 p.

5. Bryce J, Boschi-Pinto C, Shibuya K, Black RE; WHO Child Health Epidemiology Reference Group. WHO estimates of the causes of death in children. Lancet 2005;365:1147-52.

6. Fauveau V. Assessing probable causes of death without death registration or certificates: a new science? Bull World Health Organ 2006;84:246-7.

7. World Health Organization. WHO technical consultation on verbal autopsy tools: final report. Geneva: World Health Organization, 2005. 45 p.

8. International Centre for Diarrhoeal Disease Research, Bangladesh. Health and demographic surveillance system-Matlab. V. 35. Registration of health and demographic events 2002. Dhaka: International Centre for Diarrhoeal Disease Research, Bangladesh, 2004. 92 p. (ICDDR,B scientific report no. 91).

9. Bangladesh. Ministry of Health and Family Welfare. Integrated management of childhood illness: management of the sick young infant age 1 day up to 2 months. Dhaka: Ministry of Health and Family Welfare, Bangladesh, 2006. $64 \mathrm{p}$.

10. World Health Organization. International statistical classification of diseases and related health problems. $10^{\text {th }}$ Rev. V. 2: Instruction manual. Geneva: World Health Organization, 1993:130-2.

11. StataCorp. Stata statistical software: release 9. College Station, TX: SataCorp LP, 2005.

12. International Centre for Diarrhoeal Disease Research, Bangladesh. Health and demographic surveillance system-Matlab. V. 39. Registration of health and demographic events 2005. Prepared by G. Mostafa and M.M. Rahman. Dhaka: International Centre for Diarrhoeal Disease Research, Bangladesh, 2007. 119 p. (ICDDR,B scientific report no. 97).

13. Hale L, DaVanzo J, Razzaque A, Rahman M. Why are infant and child mortality rates lower in the MCH-FP area of Matlab, Bangladesh? Stud Fam Plann 2006;37:281-92.

14. Mercer A, Haseen F, Huq NL, Uddin N, Khan MH, Larson CP. Risk factors for neonatal mortality in ru- ral areas of Bangladesh served by a large NGO programme. Health Policy Plan 2006;21:432-43.

15. Velaphi S, Pattinson R. Avoidable factors and causes of neonatal deaths from perinatal asphyxia-hypoxia in South Africa: national perinatal survey. Ann Trop Paediatr 2007;27:99-106.

16. Yasmin S, Osrin D, Paul E, Costello A. Neonatal mortality of low-birth-weight infants in Bangladesh. Bull World Health Organ 2001;79:608-14.

17. Bang AT, Bang RA, Baitule SB, Reddy HM, Deshmukh MD. Management of birth asphyxia in home deliveries in rural Gadchiroli: the effect of two types of birth attendants and of resuscitating with mouth-to-mouth, tube-mask or bag-mask. J Perinatol 2005;25(Suppl):S82-91.

18. Bari W, Chowdhury RI, Islam MA, Chakraborty N, Akhter HA. The differentials and determinants of perinatal mortality in rural Bangladesh. Eur J Contracept Reprod Health Care 2002;7:216-22.

19. Baqui AH, Darmstadt GL, Williams EK, Kumar V, Kiran TU, Panwar D et al. Rates, timing and causes of neonatal deaths in rural India: implications for neonatal health programmes. Bull World Health Organ 2006;84:706-13.

20. Chowdhury ME, Akhter HH, Chongsuvivatwong V, Geater AF. Neonatal mortality in rural Bangladesh: an exploratory study. J Health Popul Nutr 2005;23:16-24.

21. Wells JC. Natural selection and sex differences in morbidity and mortality in early life. J Theor Biol 2000;202:65-76.

22. Bang AT, Baitule SB, Reddy HM, Deshmukh MD, Bang RA. Low birth weight and preterm neonates: can they be managed at home by mother and a trained village health worker? J Perinatol 2005;25(Suppl1):S72-81.

23. Palme-Kilander C. Methods of resuscitation in lowApgar-score newborn infants-a national survey. Acta Paediatr 1992;81:739-44.

24. Wall SN, Lee AC, Niermeyer S, English M, Keenan WJ, Carlo W et al. Neonatal resuscitation in low-resource settings: what, who, and how to overcome challenges to scale up? Int J Gynaecol Obstet 2009;107(Suppl 1):S47-62, S63-4.

25. Bhutta ZA, Darmstadt GL, Hasan BS, Haws RA. Community-based interventions for improving perinatal and neonatal health outcomes in developing countries: a review of the evidence. Pediatrics 2005;115(2 Suppl):519-617.

26. World Health Organization. Collaborative Study Team. Effect of breastfeeding on infant and child mortality due to infectious diseases in less developed countries: a pooled analysis. WHO Collaborative Study Team on the Role of Breastfeeding on the Prevention of Infant Mortality. Lancet 2000;355:451-5.

27. Conde-Agudelo A, Diaz-Rossello JL, Belizan JM. Kangaroo mother care to reduce morbidity and mortali- 
ty in low birthweight infants. Cochrane Database Syst Rev 2003:CD002771.

28. Quasem I, Sloan NL, Chowdhury A, Ahmed S, Winikoff B, Chowdhury AM. Adaptation of kangaroo mother care for community-based application. J Perinatol 2003;23:646-51.

29. Christensson K, Bhat GJ, Amadi BC, Eriksson B, Höjer B. Randomised study of skin-to-skin versus incubator care for rewarming low-risk hypothermic neonates. Lancet 1998;352:1115.

30. McClure EM, Goldenberg RL, Brandes N, Darmstadt GL, Wright LL; CHX Working Group, Armbruster D et al. The use of chlorhexidine to reduce maternal and neonatal mortality and morbidity in low-resource settings. Int J Gynaecol Obstet 2007;97:89-94.

31. Darmstadt GL, Bhutta ZA, Cousens S, Adam T, Walker N, de Bernis L; Lancet Neonatal Survival Steering Team. Evidence-based, cost-effective interventions: how many newborn babies can we save? Lancet 2005;365:977-88.

32. Darmstadt GL, Black RE, Santosham M. Research priorities and postpartum care strategies for the prevention and optimal management of neonatal infec- tions in less developed countries. Pediatr Infect Dis J 2000;19:739-50.

33. World Health Organization. Management of the child with a serious infection or a severe malnutrition: guidelines for care of the first referral level in developing countries. Hong Kong: Department of Child and Adolescent Health and Development, World Health Organization, 2000. 162 p. (WHO/FCH/CAH/00.1).

34. World Health Organization. Integrated management of childhood illness (IMCI): Assess and classify the sick young infant 1 week up to 2 months. Geneva: Division of Child Health and Development, World Health Organization, 2001. 34 p.

35. Bang AT, Bang RA, Baitule SB, Reddy MH, Deshmukh MD. Effect of home-based neonatal care and management of sepsis on neonatal mortality: field trial in rural India. Lancet 1999;354:1955-61.

36. Baqui AH, Arifeen SE, Darmstadt GL, Ahmed S, Williams EK, Seraji HR et al. Effect of community-based newborn-care intervention package implemented through two service-delivery strategies in Sylhet district, Bangladesh: a cluster-randomised controlled trial. Lancet 2008;371:1936-44. 